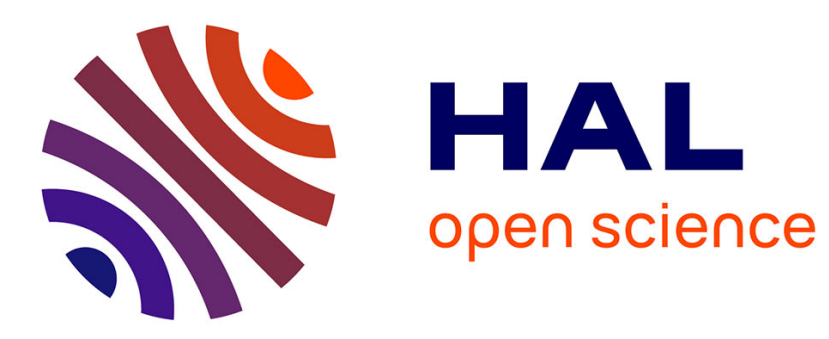

\title{
Credit rationing, profit accumulation and economic growth
}

\author{
Jean-Bernard Chatelain, Bruno Amable, Kirsten Ralf
}

\section{To cite this version:}

Jean-Bernard Chatelain, Bruno Amable, Kirsten Ralf. Credit rationing, profit accumulation and economic growth. Economics Letters, 2004, 117 (4), pp.301-307. 10.1016/j.econlet.2004.03.034 . halshs-00112521

\section{HAL Id: halshs-00112521 https://shs.hal.science/halshs-00112521}

Submitted on 9 Dec 2006

HAL is a multi-disciplinary open access archive for the deposit and dissemination of scientific research documents, whether they are published or not. The documents may come from teaching and research institutions in France or abroad, or from public or private research centers.
L'archive ouverte pluridisciplinaire HAL, est destinée au dépôt et à la diffusion de documents scientifiques de niveau recherche, publiés ou non, émanant des établissements d'enseignement et de recherche français ou étrangers, des laboratoires publics ou privés. 


\title{
Credit Rationing, Profit Accumulation
}

\section{and Economic Growth*}

\author{
Bruno Amable ${ }^{\dagger} \quad$ Jean-Bernard Chatelain ${ }^{\ddagger} \quad$ Kirsten Ralf $^{\S}$ \\ Post Print: Economics Letters (2004), 85, pp. 301-307.
}

\begin{abstract}
This paper studies how credit rationing affects endogenous growth when capital and debt are related to the firm's internal net worth, taken as collateral. The accumulation of firm's net worth determines the growth rate of capital and the growth rate of the economy. The relation between growth and interest rate is then negative without requiring convex adjustment costs on investment.

JEL classification number: O16.
\end{abstract}

Keywords: Endogenous Growth, Investment, Credit Rationing.

* We would like to thank an anonymous refereee for his very helpful comments.

$\dagger$ University of Paris 1, PSE and CEPREMAP, 48 Boulevard Jourdan, F-75014, Paris France. E-mail address: bruno.amable@cepremap.cnrs.fr

$¥$ PSE, CEPREMAP and Economix, University Paris 10. E-mail address: jeanbernard.chatelain@u-paris10.fr

$\S$ Corresponding Author: The American University of Paris; ESLSCA School of Management and CEPREMAP. E-mail address: Ralfkirsten@aol.com 


\section{Introduction}

Economic theory and empirical work has put forward the role of financial ratios on growth (e.g. Demirgüc-Kunt and Levine [2001]). The role of collateral requirements has been recently emphasized in empirical work on investment and in business cycle models (e.g. Kiyotaki and Moore [1997]). If the capital stock faces a finance constraint related to internal net worth - as claimed by business cycle theorists - and if capital growth determines output growth - as claimed by endogenous growth theorists -, one expects a stock/flow relationship such that the growth rate of internal funds, driven by retained earnings of financially constrained firms, has an impact on economic growth. Earnings are related to the gap between the marginal productivity of capital and the interest rate, due to credit rationing. This intertemporal effect of credit rationing leads to a negative relationship between the interest rate and economic growth. It is a theoretical alternative to convex adjustment cost on investment in order to obtain this negative relationship in endogenous growth models (Barro and Sala-I-Martin [1992]).

This note is organised as follows. In section 2 are presented households' and entrepreneurs' behaviour and growth regimes. Section 3 concludes. 


\section{The model}

\subsection{Wage-earners and Entrepreneurs}

A continuum of wage-earners, distributed on $[0, L]$, maximizes a constant intertemporal elasticity of substitution utility function discounted over an infinite horizon: $U_{t}=\sum_{\tau=0}^{+\infty} u\left(c_{t+\tau}\right)(1+\rho)^{-\tau}$ with $u\left(c_{t}\right)=\left(c_{t+\tau}^{1-\sigma}-1\right) / 1-\sigma$ for $\sigma>0$ and $\sigma \neq 1$ or with $u\left(c_{t}\right)=\ln \left(c_{t}\right)$ for $\sigma=1$. Consumption at time $t$ is $c_{t}$, the rate of time preference is $\rho>0$, and the inverse of the elasticity of substitution is $\sigma$. Households supply inelastically one unit of labor paid at a real wage rate $w_{t}$ and they have no disutility of labor. They lend to entrepreneurs and earn a rate of return $r$ on their individual wealth $b_{t-1}^{h}$ so that their wealth dynamics is given by $b_{t}^{h}=(1+r) b_{t-1}^{h}+w_{t}-c_{t}$. The initial wealth $b_{0}^{h}$ is given and identical for all households. Then, optimal consumption growth $g_{c}$ is given by $1+g_{c}=c_{t+1} / c_{t}=C_{t+1} / C_{t}=((1+r) /(1+\rho))^{\frac{1}{\sigma}}$ where $C_{t}=c_{t} L$ denotes aggregate consumption. $U_{0}$ is bounded if $(1+r)^{1-\sigma}<1+\rho$. For $\sigma \geq 1$ this condition is fulfilled as long as $r>\rho=r_{\min }^{c}$. For $\sigma<1$, the interest rate has to be chosen such that $1+r \in] 1+\rho,(1+\rho)^{1 /(1-\sigma)}[=] 1+r_{\min }^{c}, 1+r_{\max }^{c}[$.

A continuum of risk neutral entrepreneurs, distributed on $[0,1]$, can borrow or lend at the rate $r$ and maximise the present value $V$ of dividends $d_{t}$ that they consume: $V_{t}=\sum_{\tau=1}^{\tau=+\infty} d_{t+\tau}(1+r)^{-\tau}$. They hold an initial wealth $e_{0}$ that they invest into equity in their own firm. They have access to a Romer [1986] learning-by-doing technology where production of a single firm $y_{t}$ is a linear homogeneous function $F$ with constant return to scale of its capital input $k_{t}$ and its labor input $l_{t}$; which also depends on the 
aggregate capital stock $K_{t}$, representing the uncompensated spillovers of knowledge or ideas from one producer to another. Production is subject to diminishing returns in $k_{t}$ for fixed $K_{t}$ but constant returns with respect to $k_{t}$ and $K_{t}$ together. Production also depends on the entrepreneur specific human capital input $h_{t}$, which induces no disutility. Were the entrepreneur to withdraw her specific human capital (the dichotomous variable $1_{h_{t}>0}$ equals zero instead of one), production would be zero, so that: $y_{t}=1_{h_{t}>0} \cdot F\left(k_{t}, l_{t} K_{t}\right)=1_{h_{t}>0} \cdot k_{t} F\left(1,\left(l_{t} / k_{t}\right) K_{t}\right)$.

An entrepreneur has always the ability to threaten its creditors by withdrawing her human capital input, repudiate its debt contract, and find other creditors in $[0,1]$ for future periods. Creditors (households) protect themselves by collateralizing the stock of capital and take care never to let the size of the debt repayment to exceed the value of the collateral after depreciation at the end of the period, so that $(1+r) b_{t} \leq$ $(1-\mu)(1-\delta) p^{I} k_{t}$ where $\delta$ is the depreciation rate with $0 \leq \delta<1$ and where $p^{I}$ is the price of capital in units of consumables assumed to be constant and exogenous. Lenders may loose a proportion $(1-\mu)$, with $0 \leq \mu<1$, of collateralized capital because of bankruptcy costs. In this Kiyotaki and Moore's [1997] setting, debt $b_{t}$ is a prefered means of finance rather than new share issues.

Dividends $d_{t}$ are given by the firm's flow of funds constraint that states that cash inflows include net revenues $y_{t}$ and net borrowing $b_{t}-b_{t-1}$, while cash outflows consist of dividends $d_{t}$, wage payment $w_{t} l_{t}$, interest payment $r b_{t-1}$ and investment expendi- 
tures and $k_{t}-(1-\delta) k_{t-1}$ is investment:

$$
d_{t}=F\left(k_{t}, K_{t} l_{t}\right)-w_{t} l_{t}-r b_{t-1}+b_{t}-b_{t-1}-p^{I}\left(k_{t}-(1-\delta) k_{t-1}\right)
$$

We may assume that entrepreneurs consume at least an amount equal to a fraction $d_{m} \geq 0$ of their last period capital sold at current price in order to avoid the situation in which the entrepreneurs continually postpone consumption: $d_{t}-d_{m} p^{I} k_{t-1} \geq 0$. The entrepreneurs maximize the present value of dividends given by the flow of funds constraint, taking into account production possibilities, and the credit and dividends inequality constraints. They determine the optimal amounts of labor, capital and debt by maximizing the following Lagrangian:

$$
\sum_{t=0}^{t=+\infty}\left(\frac{1}{1+r}\right)^{t}\left(d_{t}+\lambda_{t}^{d}\left(d_{t}-d_{m} p^{I} k_{t-1}\right)+\lambda_{t}^{b}\left((1-\mu)(1-\delta) p^{I} k_{t}-(1+r) b_{t}\right)\right)
$$

$\lambda_{t}^{d}$ is the Lagrangian multiplier associated with the constraint on producers' consumption and $\lambda_{t}^{b}$ is the Lagrangian multiplier associated with the credit constraint. The marginal condition on labor leads to $w_{t}=F_{l_{t}}\left(k_{t}, K_{t} \cdot l_{t}\right)=F_{l_{t}}\left(1, K_{t} l_{t} / k_{t}\right)$, the one on debt is $\lambda_{t}^{d}-\lambda_{t+1}^{d}=\lambda_{t}^{b}(1+r) \geq 0$ and the one on capital is given by:

$$
\left(1+\lambda_{t}^{d}\right)\left(F_{k_{t}}\left(k_{t}, K_{t} \cdot l_{t}\right)-p^{I}\right)+\lambda_{t}^{b}(1-\mu)(1-\delta) p^{I}+\left(1+\lambda_{t+1}^{d}\right) \frac{1-\delta}{1+r} p^{I}-\frac{\lambda_{t+1}^{d} d_{m} p^{I}}{1+r}=0
$$

or: 


$$
\frac{F_{k_{t}}\left(k_{t}, K_{t} \cdot l_{t}\right)}{p^{I}}=1-\frac{1-\delta}{1+r}+\mu\left(\frac{\lambda_{t}^{d}-\lambda_{t+1}^{d}}{1+\lambda_{t}^{d}}\right) \frac{1-\delta}{1+r}+\frac{\lambda_{t+1}^{d}}{1+\lambda_{t}^{d}} \frac{d_{m}}{1+r}
$$

Taking into account the inequality conditions, we can distinguish 2 cases of interest (the two other cases $\left(\lambda_{t}^{b}=0, \lambda_{t}^{d} \neq 0\right.$, or $\left.\lambda_{t}^{b} \neq 0, \lambda_{t}^{d}=0\right)$ are either irrelevant or transitory). As all firms have an identical initial endowment of net worth, recursive properties of marginal conditions implies that the credit and entrepreneurs consumption constraints are binding for all firms or for none of them, after the second period.

The first case, $\lambda_{t}^{b}=0, \lambda_{t}^{d}=0$, reflects the fact that neither the credit constraint nor the constraint on producers' consumption is binding. From the marginal condition on debt $\lambda_{t}^{d}-\lambda_{t+1}^{d}=\lambda_{t}^{b}(1+r)$ we can conclude that $\lambda_{t+1}^{d}=0$, i.e. the constraint on producer's consumption does not bind in the next period. The amount of debt is indeterminate, as expected by the Modigliani-Miller theorem. The individual and aggregate marginal product of capital is equal to Jorgenson's neo-classical user cost of capital (linearly approximated by $p^{I}(r+\delta)$ ), so that the interest rate $r^{*}$ is such that $1+r^{*}=(1-\delta) /\left(1-\frac{F_{k_{t}}\left(K_{t}, K_{t} L\right)}{p^{I}}\right)$.

When both constraints are binding $\left(\lambda_{t}^{b} \neq 0, \lambda_{t}^{d} \neq 0\right)$, the marginal product of capital is higher than Jorgenson's neo-classical user cost of capital. The minimal level of dividends can be substituted in the flow of fund constraint. Taking into account constant returns to scale and that all firms are identical and distributed over $[0,1]$, we aggregate dividends and the flow of funds equation (aggregate variables are in capital letters): 


$$
d_{m} p^{I} K_{t-1}=F\left(K_{t}, K_{t} L\right)-w_{t} L-(1+r) B_{t-1}+B_{t}-p^{I}\left(K_{t}-(1-\delta) K_{t-1}\right)
$$

Substituting $B_{t} / K_{t-1}=\left(B_{t} / K_{t}\right)\left(K_{t} / K_{t-1}\right)$, one finds an intermediate implicit equation shows that the growth rate of aggregate (and individual capital) is equal to the growth rate of internal funds (retained earnings over equity) which depends on current and lagged values of capital and debt:

$$
g_{K}=\frac{K_{t}}{K_{t-1}}-1=\frac{1-d_{m}-\delta+\left(\frac{F\left(k_{t}, K_{t} L\right)-w_{t} L}{p^{I} K_{t-1}}-(1+r) \frac{B_{t-1}}{p^{I} K_{t-1}}\right)}{1-\frac{B_{t}}{p^{I} K_{t}}}-1
$$

The average profit rate is $\pi_{t}=\left(F\left(K_{t}, K_{t} L\right)-w_{t} L\right) / p^{I} K_{t-1}=F_{k_{t}}\left(K_{t}, K_{t} L\right) \frac{K_{t}}{p^{I} K_{t-1}}$ - At the entrepreneur level and at the aggregate level, the profit rate depends on the optimal labor-capital ratio which is determined by the marginal condition on labour as: $F\left(K_{t}, K_{t} L\right)=F\left(1, K_{t} \cdot\left(l_{t} / k_{t}\right)\right)$. A second step consists of aggregating the linear binding credit constraint $b_{t}=(1-\mu) \frac{1-\delta}{1+r} p^{I} k_{t}$, take as given that the credit constraint has been binding also the date before, and replace aggregate leverage to get the explicit growth rate of aggregate capital:

$$
g_{K}=\frac{K_{t}}{K_{t-1}}-1=\frac{\mu(1-\delta)-d_{m}}{1-(1-\mu)\left(\frac{1-\delta}{1+r}\right)-\frac{F_{k_{t}}\left(K_{t}, K_{t} L\right)}{p^{I}}}-1
$$


In what follows, we assume that entrepreneurs minimal consumption level is sufficiently small: $d_{m}<\mu(1-\delta)$. Then, $1-\left(\frac{1-\delta}{1+r}\right)(1-\mu)>\frac{F_{k_{t}}\left(K_{t}, K_{t} L\right)}{p^{I}}$, else $g_{K}<-1$. The aggregate growth rate of capital is decreasing when the interest rate increases for two reasons: a negative effect of interest charges on retained earnings and a negative effect on endogenous leverage. Furthermore, we restrict the parameter values in such a way that the entrepreneurs' utility will be bounded when taking into account the growth rate of capital (and when the entrepreneur does not know that the steady state interest rate $r$ is endogenous):

$$
V_{0}=\frac{d_{m} p^{I} k_{0}}{1+r} \sum_{t=0}^{\infty}(1+r)^{-t} \cdot\left(\frac{\mu(1-\delta)-d_{m}}{1-(1-\mu) \frac{1-\delta}{1+r}-\frac{F_{k_{t}}\left(K_{t}, K_{t} L\right)}{p^{I}}}\right)^{t}
$$

The objective function is bounded, if $g_{K}<r$ :

$$
\frac{1}{1+r} \frac{\mu(1-\delta)-d_{m}}{1-(1-\mu) \frac{1-\delta}{1+r}-\frac{F_{k_{t}}\left(K_{t}, K_{t} L\right)}{p^{I}}}<1
$$

That is:

$$
1+r>1+r_{\min }^{K}=\frac{1-\delta-d_{m}}{1-F_{k_{t}}\left(k_{t}, K_{t} l_{t}\right) / p^{I}}
$$

\subsection{Balanced growth}

For a balanced growth to exist in the economy we have to find an interest rate, such that the growth rate of capital equals the growth rate of consumption: $g^{*}=g_{K}=g_{C}$. We restrict the parameter values to ensure bounded utilities over a positive balanced 
growth for households $(r \in] r_{\min }^{c}, r_{\max }^{c}[)$ and for entrepreneurs. For Romer's [1986] case of unconstrained growth, substituting the interest rate $r^{*}$ (for a bounded utility) in the condition for the growth rate of consumption yields:

$$
1+g^{*}=\left(\frac{\frac{1-\delta}{1-\frac{F_{k_{t}}\left(K_{t}, K_{t} L\right)}{p^{I}}}}{1+\rho}\right)^{\frac{1}{\sigma}}
$$

This growth rate is positive when the marginal product of capital is be larger than the rate of time preference. Growth increases with the return on savings and decreases with the rate of time preference and the elasticity of substitution.

A steady state credit constrained economy exists provided that a steady state interest rate $r^{F C}$ exists such that the growth rate of capital (decreasing with interest rate) equals the growth rate of consumption (increasing with interest rate):

$$
H(r)=g_{K}(r)-g_{C}(r)=\frac{\mu(1-\delta)-d_{m}}{1-(1-\mu) \frac{1-\delta}{1+r}-\frac{F_{k_{t}}\left(K_{t}, K_{t} L\right)}{p^{I}}}-\left(\frac{1+r}{1+\rho}\right)^{\frac{1}{\sigma}}=0
$$

The intermediate value theorem provides conditions for the existence of $r^{F C} . H(r)$ is continuous for $1+r>(1-\mu)\left(1+r^{*}\right)$ and strictly decreasing if and only if there is an upper limit on entrepreneurs' minimal consumption: $d_{m}<d_{1}=\mu(1-\delta)$. The economy is credit constrained if and only if the neo-classical user cost of capital is lower than the marginal product of capital. The two following conditions are equivalent (as $(1+r) /(1+\rho)>0)$, so that the credit constrained interest rate and growth rate are 
always lower than in Romer's steady state growth regime:

$$
1+r^{F C}<1+r^{*}=\frac{1-\delta}{1-\frac{F_{k_{t}}\left(K_{t}, K_{t} L\right)}{p^{I}}} \Leftrightarrow\left(\frac{1+r^{F C}}{1+\rho}\right)^{\frac{1}{\sigma}}<1+g^{*}
$$

Hence, $r^{F C}<r^{*}$ if and only if:

$$
H\left(r^{*}\right)<0 \Leftrightarrow \frac{\mu(1-\delta)-d_{m}}{1-(1-\mu) \frac{1-\delta}{1+r^{*}}-\frac{F_{k_{t}}\left(K_{t}, K_{t} L\right)}{p^{I}}}<1+g^{*}
$$

That is:

$$
d_{m}>d_{\min }=\mu \cdot\left(\frac{F_{k_{t}}\left(K_{t}, K_{t} L\right)}{p^{I}}\left(1+g^{*}\right)-\delta-g^{*}\right)
$$

The entrepreneurs are credit constrained in the steady state despite they are profitable, because they pay-out a fraction of profits as dividend above a minimal threshold and do not have enough own saving to cover the down-payment for acquiring more capital. The credit constrained steady state growth rate is always positive when $1+\rho<(1-\mu)\left(1+r^{*}\right)$, as $\lim _{1+r \rightarrow(1-\mu)\left(1+r^{*}\right)} H\left((1-\mu)\left(1+r^{*}\right)\right)=+\infty>0$. Else, one has to check that $H(\rho)>0$ if and only if $g_{K}(\rho)>0$, which leads to another upper limit on entrepreneurs' minimal consumption:

$$
d_{m}<d_{2}=\frac{F_{k_{t}}\left(K_{t}, K_{t} L\right)}{p^{I}}+(1+\rho \mu) \frac{1-\delta}{1+\rho}-1
$$

Finally, wage-earners and entrepreneurs intertemporal utility functions are bounded, 
so that $H\left(r_{\max }\right)<0$ with $r_{\max }=\min \left(r_{\max }^{c}, r_{\max }^{K}, r^{*}\right)$.

These conditions are indeed feasible. In the Cobb Douglas case $\left(y_{t}=A k_{t}^{1-\alpha}\left(K_{t} l_{t}\right)^{\alpha}\right.$, with $0<\alpha<1)$, one has $F_{k_{t}}\left(k_{t}, K_{t} l_{t}\right)=(1-\alpha) A\left(\frac{w}{\alpha A K}\right)^{\frac{\alpha}{\alpha-1}}$. Once the externality is taken into account, $F_{k_{t}}\left(K_{t}, K_{t} L\right)=(1-\alpha) A L^{\alpha}$. A numerical example is given by the following choice of parameter values: $A=0.23, L=2, \alpha=0.7, p^{I}=1$, $\delta=8 \%, \sigma=0.7, \rho=0.02, \mu=40 \%$, and $d_{\text {min }} \simeq 0.47 \%<d_{m}=1 \%<d_{2} \simeq 2,1 \%<$ $d_{1} \simeq 36.8 \%$. Then $r_{\min }^{c}=\rho=2 \%, r_{\max }^{c} \simeq 6.8 \%, r_{\min }^{K} \simeq 2.5 \%$. In Romer's [1986] case, the (real) interest rate is $r^{*} \simeq 3.6 \%$ and the growth rate is $g^{*} \simeq 2.3 \%$. The financially constrained regime corresponds to an interest rate $r^{F C} \simeq 3.1 \%$, included in the feasible interval, for an output growth rate of $g^{F C} \simeq 1.6 \%$.

\section{Conclusion}

This note shows how the growth rate of internal funds drives the growth rate of capital and of economic growth when firms are facing credit rationing and a Romer like externality. An extension could model cyclical endogenous growth with credit rationing.

\section{References}

[1] Barro R.J. and Sala-I-Martin X. [1992]. Public Finance in Models of Economic Growth. Review of Economic Studies. 41, 797-805.59, 645-661. 
[2] Kiyotaki N. and Moore J. [1997]. Credit Cycles. Journal of Political Economy. 105(2), 211-248.

[3] Demirgüç-Kung A. and Levine R. [2001]. Financial Structure and Economic Growth. MIT Press. Cambridge.

[4] Romer, P. [1986] Increasing Returns and Long Run Growth. Journal of Political Economy. 94(5) 1002-1037. 